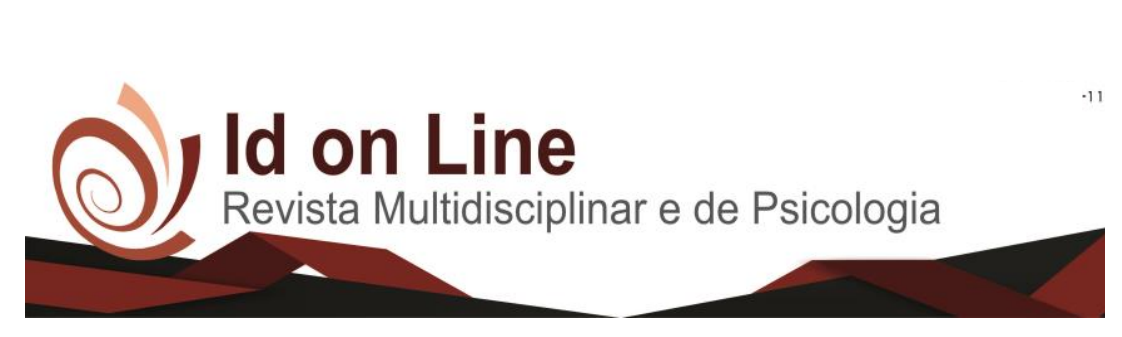

DOI: 10.14295/idonline.v13i46.1991

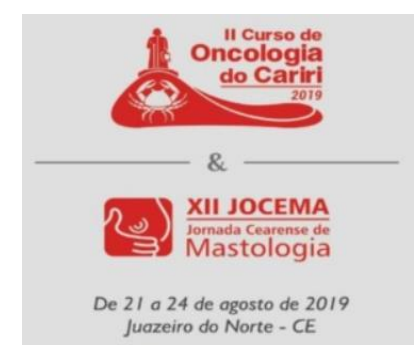

Resumo

\title{
DIETOTERAPIA NA EQUIPE INTERDISCIPLINAR PARA O TRATAMENTO DE CÂNCER DO OVÁRIO
}

\author{
Ana Clara Lacerda Cervantes de Carvalho'; Waldeir de Souza Ferreira Júnior ${ }^{1}$; \\ Suanam Altair Tavares de Menezes ${ }^{1}$; Mariana Machado Bueno ${ }^{2}$.
}

\begin{abstract}
Introdução: o câncer do ovário é um dos mais incidentes e a segunda neoplasia ginecológica mais comum nas regiões do Brasil, estimando 6.150 novos casos entre os anos de 2018 e 2019, refere-se a alterações na expressão do padrão de genes, que na maioria dos casos, agridem as células epiteliais e germinativas, ocasionando vários déficits nutricionais, principalmente, o energético-protéico. Objetivo: o objetivo do estudo foi analisar o protocolo nutricional, pela equipe multidisciplinar, no tratamento para o câncer do ovário. Método: trata-se de uma revisão sistemática sem metanálise da literatura nas bases de dados LILACS e SCIELO, com buscas realizadas em julho de 2019, utilizando os descritores associados ao operador booleano (AND): Dietoterapia. Multidisciplinar. Câncer do ovário. Os critérios de inclusão foram estudos disponíveis em português e inglês, publicados entre os anos de 2011 a 2018, excluindo os que não abordassem a temática. Resultados: Foram selecionados 9 artigos, após a aplicação dos critérios, restaram 5 artigos. Apesar do difícil diagnóstico e de não apresentar sintomatologia específica, muitas vezes confundindo-se com outras patologias, e além de não haver um método de diagnóstico de fácil execução e aplicável nas mulheres, dificultando assim o tratamento e a expectativa de sobrevida da paciente, prevalecendo a taxa de mortalidade elevada. Diante disso, o tratamento ofertado pela equipe de saúde garante a assistência integral para a compressão da neoplasia. No contexto nutricional, o nutricionista auxilia na manutenção e evolução dietoterápica do paciente para o melhor desempenho das demais terapêuticas, como cirurgia e quimioterapia, dependendo do estadiamento da doença e da condição clínica; na redução da sintomatologia, como dores, distensão abdominal, redução do apetite e sensação de saciedade precoce, isto posto, influencia na recuperação e na estabilização do caso, fracionando a dieta diária, de acordo com a aceitação alimentar, estimulando a ingestão hídrica, provendo o consumo de alimentos como frutas e hortaliças que contenham antioxidantes. Conclusão: a dietoterapia é fundamental para o tratamento do câncer do ovário, ofertando as recomendações nutricionais ideias conforme os dados da avalição nutricional e o grau de manifestação clínica, apresentando-se imprescindível na equipe multiprofissional durante a terapêutica, abrangendo a individualidade de cada paciente.
\end{abstract}

Palavras-Chave: Dietoterapia. Multidisciplinaridade. Neoplasia ovariana.

\footnotetext{
${ }^{1}$ Discente do Curso de Nutrição da Faculdade de Juazeiro do Norte- FJN;

2 Docente do Curso de Nutrição da Faculdade de Juazeiro do Norte- FJN;

Autor Correspondente: lacerdaana00@ gmail.com.
} 


\section{Referências:}

ANSTEY, E. H.; SHOEMAKER, M. L.; BARRERA, C. M.; NEIL, M. B., VERMA, A. B.; HOLMAN, D. M. Breastfeeding and Breast Cancer Risk Reduction: Implications for Black Mothers. American Journal of Preventive Medicine, v.53, n.3, 2017.

DOI: 10.1016/j.amepre.2017.04.024.

OLIVEIRA, V. A. Efeitos da imunonutrição no tratamento de pacientes com câncer e suas complicações. Semina: Ciências Biológicas e da Saúde, v. 35, n. 2, 2015.

DOI: $10.5433 / 1679-0367.201 v 36 n 1 p 107$.

PANIS, C. et al. Revisão crítica da mortalidade por câncer usando registros hospitalares e anos potenciais de vida perdidos. Revista Einstein (São Paulo), v.16, n.1, 2018.

DOI: $10.1590 / \mathrm{S} 1679-45082018 \mathrm{AO} 4018$.

ROHENKOHL, C. C.; CARNIEL, A. P.; COLPO, E. Consumo de antioxidantes durante tratamento quimioterápico. ABCD - Arquivos Brasileiros De Cirurgia Digestiva, v. 24, n. 2, 2011. DOI: 10.1590/S0102-67202011000200004.

SILVA, M. R. F.; BRAGA, J. P. R.; MOURA, J. F. P.; LIMA, J. T. O. Continuidade Assistencial a mulheres com câncer de colo de útero em redes de atenção à saúde: estudo de caso, Pernambuco. Saúde debate, v. 40, n. 110, 2016. DOI: 10.1590/0103-1104201611008. 